\title{
O ATENDIMENTO DA EDUCAÇÃO INFANTIL VIA CONVENIAMENTO: UM ESTUDO DAS JUSTIFICATIVAS MUNICIPAIS
}

\section{THE KINDERGARTEN SERVICE THROUGH PARTNERSHIPS: A STUDY OF THE MUNICIPAL JUSTIFICATIONS}

\begin{abstract}
COSTA, Beatriz Aparecida da
biadisquete@hotmail.com

Universidade Estadual Paulista "Júlio de Mesquita Filho" - Rio Claro/SP

BORGHI, Raquel Fontes

raborghi@gmail.com

Universidade Estadual Paulista “Júlio de Mesquita Filho" - Rio Claro/SP
\end{abstract}

\begin{abstract}
RESUMO Este artigo é resultado de uma pesquisa realizada no ano de 2011 que teve por objetivo estudar as parcerias entre municípios paulistas e instituições privadas para a oferta de vagas na Educação Infantil. Tal pesquisa parte de um estudo anterior que identificou um grande número de parcerias dessa modalidade em municípios do estado de São Paulo (ADRIÃO, 2009). Fizeram parte do estudo 28 municípios paulistas de pequeno porte, o que representa $50 \%$ do total de municípios pequenos que declararam adotar esse tipo de parceria na pesquisa anterior. Os dados que serão aqui apresentados foram coletados por meio de contatos telefônicos com o Dirigente Municipal de Educação e/ou com o responsável pela Educação Infantil de cada um dos municípios estudados. Neste artigo, o objetivo específico é analisar, pela perspectiva da abordagem qualitativa, as justificativas dos municípios pesquisados para a opção pelas parcerias com instituições privadas de Educação Infantil. Apontamos como resultado a predominância das justificativas que envolvem a necessidade de satisfazer a demanda municipal referente à Educação Infantil e de auxiliar instituições privadas sem fins lucrativos que, sem os recursos municipais, deixariam de realizar $o$ atendimento.
\end{abstract}

PALAVRAS-CHAVE: Parceria público-privada. Educação Infantil. Justificativas municipais. Desresponsabilização.

ABSTRACT This article is the result of a survey conducted in 2011 which aimed to study partnerships between municipalities and private institutions in São Paulo for the supply of vacancies in Child Education. Such research started with a previous study that identified a large number of this type of partnership in counties of the state of São Paulo (Adrian, 2009). Study participants were 28 small counties, representing 
$50 \%$ of total small municipalities that claim to adopt this type of partnership in the previous research. The data to be presented here was collected by telephone contacts with the Municipal Director of Education and/or the responsible for Child Education in each city studied. In this article, the specific objective is analyzing, using the qualitative approach, the justifications given by the municipalities surveyed for choosing the partnerships with private institutions of education. We point as a result the predominance of justifications involving the need to satisfy demand for municipal Childhood Education and the assistance to private non-profit organizations that, without municipal resources, would cease to perform the service.

KEYWORDS: Public-private Partnership. Early Childhood Education. City's justifications. Disclaimer.

\section{INTRODUÇÃO}

A Constituição Federal de 1988 e a Lei de Diretrizes e Bases da Educação Nacional (LDB, lei $n^{\circ}$ 9394/96) são importantes legislações que propiciaram considerável avanço no que diz respeito ao direito à Educação Infantil.

A LDB definiu a Educação Infantil como a primeira etapa da educação básica e a dividiu em creches e pré-escolas, dando um prazo de três anos, a partir da publicação da lei, para que as instituições desse nível educacional se integrassem aos sistemas de ensino.

Entretanto, o atendimento às crianças no Ensino Infantil não tem sido simples para os municípios, que são os responsáveis prioritários por tal etapa de ensino. Uma pesquisa de Adrião (2009) evidencia que, após o processo de municipalização do ensino e de ampliação das responsabilidades municipais para com a Educação Infantil e o Ensino Fundamental, muitas prefeituras passaram a buscar alternativas mais baratas e rápidas para esse atendimento, tais como as parcerias que são objeto deste estudo, isto é, aquelas realizadas entre o poder público municipal e instituições privadas.

Assim como Bezerra (2008), consideramos que a expressão parceria públicoprivada implica também na capacidade de intervenção que o setor privado passa a dispor junto à administração pública, por meio da assunção total ou parcial de responsabilidades até então atribuídas ao poder público em sua totalidade.

Montaño (2005, p. 146, grifos do autor) também define o termo parceria da seguinte forma: 
a chamada "parceria" não é outra coisa senão o repasse de verbas e fundos públicos no âmbito do Estado para instâncias privadas, substituindo o movimento social pela ONG. E essa verdadeira transformação de recursos públicos para setores privados não ocorre sem uma clara utilidade política governamental. O Estado é, portanto, mediante a legislação (leis como do "voluntariado" do "terceiro setor", das "Oscip", das "parcerias") e repasse de verbas, um verdadeiro subsidiador e promotor destas organizações e ações do chamado "terceiro setor" e da ilusão do seu serviço.

Historicamente, o atendimento em creches era oferecido em grande parte no âmbito assistencial, por instituições filantrópicas, comunitárias e confessionais. Muitas dessas instituições mantinham convênio ${ }^{1}$ com órgãos federais e até mesmo internacionais, como o Banco Mundial, a Unesco e o Unicef (FÜLLGRAF, 2008). Costa (2005, p. 17) afirma que tais estabelecimentos, surgidos principalmente nos anos de 1970 e 1980, tiveram duas vertentes distintas de motivações para sua constituição. Foram elas:

Por um lado, o forte discurso antiescolar, amparado em toda uma avalanche de análises que caracterizavam os sistemas educacionais sobretudo como aparelhos de dominação social e reprodução do status quo. (...) Por outro lado, agências internacionais, como o Fundo das Nações Unidas para a Infância (Unicef), associações religiosas, entidades filantrópicas e agências internas a máquinas estatais estimulavam um certo tipo de comunitarismo como forma de expandir o atendimento educacional a setores sociais excluídos do acesso a ele.

Conforme o mesmo autor, nas décadas de 1970 e 1980, o surgimento do terceiro setor em torno da assistência à faixa etária de 0 a 3 anos fundamentou-se em um forte discurso vinculado principalmente à "supremacia da gestão local, da participação comunitária" (COSTA, 2005 p. 17), em que a democracia seria exercida por meio da participação popular direta.

Com tais considerações, entende-se que os convênios/parcerias públicoprivados realizados no Brasil se constituem como uma construção cultural e histórica, cujo objetivo é de oferecer educação infantil gratuita em espaços privados (BORGHI, ADRIÃO, ARELARO, 2009).

Segundo Borghi (2012), de forma mais abrangente, as justificativas atuais para as parcerias entre o setor público e o privado tendem a se embasar no

\footnotetext{
${ }^{1}$ Convênio, de acordo com a legislação vigente (decreto ${ }^{\circ}$ 6.170, de 25 de julho de 2007), refere-se a: acordo, ajuste ou qualquer outro instrumento que discipline a transferência dos recursos financeiros de dotação consignadas nos Orçamentos Fiscais e da Seguridade Social da União e tenha como participe, de um lado, órgão ou entidade da administração pública federal, direta ou indireta, e, de outro lado, órgão ou entidade da administração público estadual, distrital ou municipal, direta ou indireta, ou ainda, entidades privadas sem fins lucrativos, visando a execução de programa de governo, envolvendo a realização de projeto, atividade, serviço, aquisição de bens ou evento de interesse recíproco, em regime de mútua cooperação.
} 
diagnóstico neoliberal de maior eficiência, maior competitividade e menor custo do setor privado. Mas, será que esses argumentos aparecem nos municípios pesquisados? Para responder a essa questão, apresentamos a seguir os dados levantados junto aos municípios pequenos ${ }^{2}$ do estado de São Paulo participantes da pesquisa.

Com a finalidade de identificar, entre outros fatores, quais eram as justificativas municipais para a realização de parcerias/convênios entre o poder público municipal e instituições privadas, foi desenvolvida uma pesquisa no ano de 2011 como Trabalho de Conclusão de Curso em Licenciatura Plena em Pedagogia, realizado na Universidade Estadual Paulista "Júlio de Mesquita Filho" - UNESP. Foram considerados nesse estudo $50 \%$ dos municípios paulistas de pequeno porte, ou seja, aqueles municípios que têm entre 10.001 e 50.000 habitantes e que declararam, em pesquisa anterior ${ }^{3}$, firmar convênios com instituições privadas para a oferta de vagas na Educação Infantil. De acordo com o Banco de Dados resultante da pesquisa anterior, dos 645 municípios paulistas, 136 declararam ter parceria para oferta de vagas na educação infantil. Dos 136 municípios identificados no Banco de Dados, selecionamos para o estudo 50\% dos municípios que apresentam de 10.001 a 50.000 habitantes, o que totaliza 28 municípios.

A pesquisa teve como objetivo geral estudar e caracterizar os arranjos que vêm sendo realizados entre o público e o privado para a oferta da primeira etapa da educação básica. A coleta dos dados ocorreu por contatos telefônicos com o Dirigente Municipal de Educação e/ou responsável pela Educação Infantil no âmbito da Secretaria Municipal de Educação. Na coleta de dados, buscamos identificar, em meio a outras informações, as justificativas para a opção pelo convênio/parceria no município, e é dessa questão pontual que trataremos neste artigo.

\footnotetext{
${ }^{2}$ Utilizou-se para separar os municípios por tamanho o critério estabelecido pelo IBGE, que considera municípios pequenos aqueles que possuem de 10.001 a 50.000 habitantes (ADRIÃO et al. 2009).

${ }^{3}$ A pesquisa "Estratégias municipais para a oferta da educação básica: uma análise de parcerias público-privadas no estado de São Paulo" foi desenvolvida durante os anos de 2007 a 2009, financiada pela Fundação de Amparo à Pesquisa do Estado de São Paulo, realizada por pesquisadores e alunos participantes do GREPPE - Grupo de Estudos e Pesquisas em Política Educacional. Teve por objetivo geral analisar a natureza e as consequências, para a oferta da educação básica, de parcerias firmadas entre sistemas municipais paulistas e setores da esfera privada. (ADRIÃO, 2009). O estudo organizou um banco de dados com informações sobre municípios paulistas que realizaram parcerias público-privadas na educação básica no período 1996-2006. As informações contidas no banco de dados evidenciaram uma ampliação das parcerias realizadas entre o Poder Público Municipal e instituições privadas na área educacional.
} 
Tal pesquisa integra um estudo de caráter interinstitucional, mais abrangente, intitulado "A oferta educacional na Educação infantil: arranjos entre o público e o privado" ${ }^{\prime 4}$, que tem por objetivo o estudo dos arranjos institucionais firmados entre o poder público municipal e instituições privadas para a oferta de Educação infantil nos municípios do Estado de São Paulo (BORGHI, 2012).

\section{O QUE OS DADOS REVELAM}

Para auxiliar na compreensão e visualização dos dados, foi elaborado um gráfico que demonstra a porcentagem e a quantidade de municípios que utilizaram determinada justificativa para a opção pelo convênio. É importante relatar que, na maioria dos casos, mais de uma justificativa foi mencionada pelo responsável pela Secretaria Municipal de Educação. Dessa forma, o número de justificativas será maior que o número de municípios pesquisados.

Não contabilizamos as justificativas dos municípios onde o convênio já havia terminado no ano de 2011. Por isso, dos 28 municípios que integraram a pesquisa, desconsideramos três (os que já extinguiram o convênio) e trabalhamos com 25, cujas justificativas totalizam 38 .

\section{Gráfico 1: Justificativas para a opção pelo convênio}

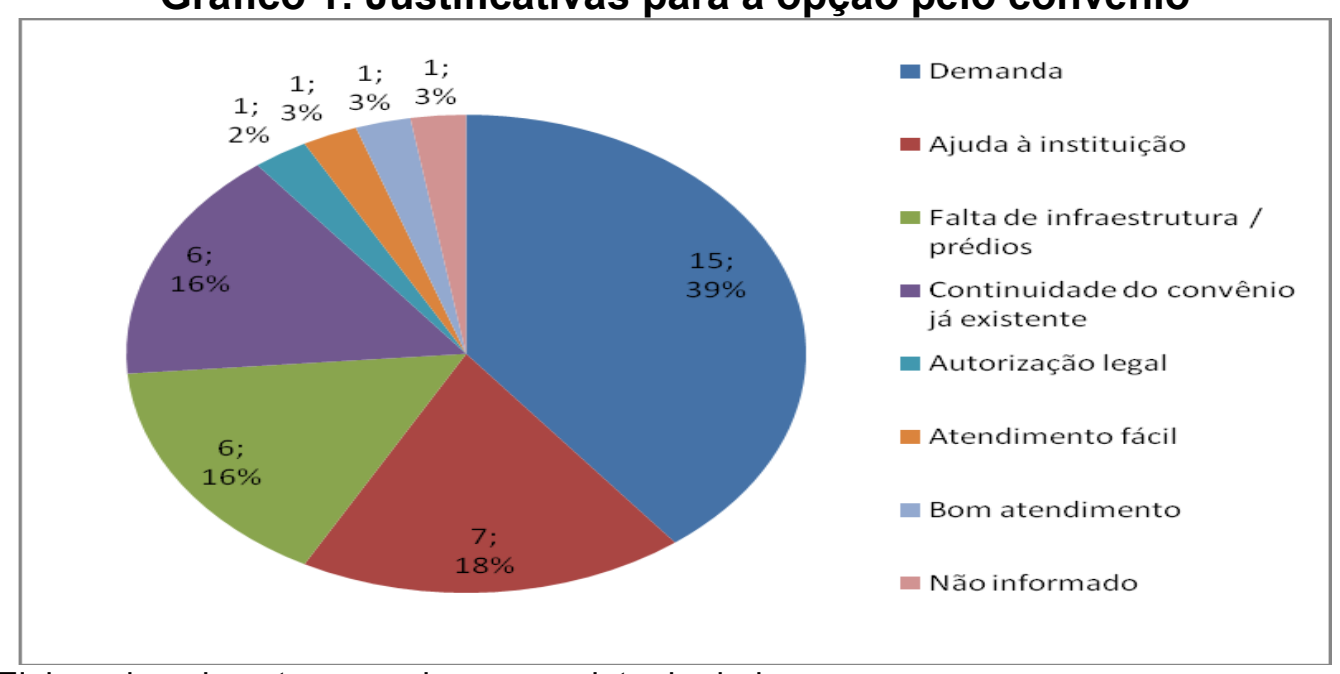

Fonte: Elaborado pela autora com base na coleta de dados.

\footnotetext{
${ }^{4}$ Projeto interinstitucional, financiado pelo CNPq, que conta com a participação das pesquisadoras: Raquel Fontes Borghi - UNESP/IB/Rio Claro (Coordenadora); Theresa Maria de Freitas Adrião - FE/UNICAMP; Teise de Oliveira Guaranha Garcia - FFCLRP/ USP Ribeirão Preto; Bianca Cristina Correa - FFCLRP/ USP Ribeirão Preto e Regiane Helena Bertagna (UNESP/RC), além de alunos de graduação e pós-graduação participante do GREPPE.
} 
A justificativa mais frequente no conjunto dos municípios pesquisados foi a referente ao atendimento da demanda, fazendo parte de $39 \%$ das respostas obtidas.

A segunda justificativa mais citada foi a ajuda à instituição, que, sem o auxílio do município, não teria condições de se manter somente com os recursos obtidos por meio de campanhas.

Em terceiro lugar, houve um empate: $16 \%$ das justificativas apontavam a falta, no município, da insfraestrutura necessária para atender ao público da Educação Infantil, e outros $16 \%$ se relacionavam à continuidade do convênio já existente na cidade, o qual foi inicialmente estabelecido pela Assistência Social ou Promoção Social e depois mantido pela Secretaria da Educação, quando a responsabilidade pela Educação Infantil migrou do primeiro órgão para o segundo.

Tivemos também algumas justificativas que apareceram somente uma vez: a do bom atendimento, a da autorização legal e a do atendimento fácil.

Na somatória das respostas, um município não soube informar por que optou pelo convênio, pois tal escolha ocorreu há muitos anos e a nova administração municipal não teve acesso à informação solicitada.

\section{O QUE AS JUSTIFICATIVAS EVIDENCIAM}

Nos municípios estudados, o auxílio às instituições sem fins lucrativos constitui uma grande parcela das justificativas para os convênios: "Ajuda às instituições" e "Continuidade do convênio já existente" somam $34 \%$ do total.

A justificativa "Continuidade do convênio já existente" nos parece ter relação com o caráter assistencial originalmente assumido pelas instituições, que não foram fundadas com finalidades educativas. Isso porque, no início, o atendimento a crianças de 0 a 3 era realizado pela Secretaria de Assistência Social/Promoção Social. Apenas quando a Educação Infantil tornou-se a primeira etapa da educação básica, em razão da LDB de 1996, é que as instituições de Educação Infantil (creches e pré-escolas) foram integradas ao sistema de ensino. Novos estudos precisam ser realizados com o objetivo de identificar se o caráter assistencial das instituições foi ou não modificado nos casos em que o convênio se manteve.

O município que não informou a justificativa relatou que o convênio também existe há muitos anos no município, indício de que provavelmente se trate de um 
caso de continuidade do convênio, mas por razões metodológicas, não somamos essa resposta ao item "Continuidade do convênio já existente".

Ao analisarmos o fato de que $35 \%$ das justificativas são voltadas para o auxílio às instituições conveniadas, consideramos que, ao mesmo tempo em que os municípios assumem "ajudar voluntariamente" tais estabelecimentos que atendem crianças pequenas, os municípios desvinculam-se de sua verdadeira obrigação, que, segundo a Constituição Federal de 1988, a LDB e o Estatuto da Criança e do Adolescente (ECA), é a de oferecer Educação Infantil àqueles que desejarem, e não a de auxiliar iniciativas de outros setores nessa área.

Em um dos municípios é possível observar claramente esse desvio, pois nele não há creche municipal, ou seja, o atendimento educacional para crianças de 0 a 3 anos é feito somente por intermédio de convênios com instituições privadas. A justificativa utilizada pelo município para a realização do convênio é a da ajuda à instituição.

Essa política pode ser analisada com base na seguinte questão: se o poder público tem o dever de oferecer um atendimento e recorre a convênios, qual das partes está ajudando a outra? O poder público está ajudando a instituição a manter seu funcionamento ou é a instituição que está ajudando o município a se desresponsabilizar pelo atendimento?

Acreditamos que, além da desresponsabilização municipal, as justificativas relacionadas ao auxílio à instituição indicam o esvaziamento da conquista de direitos, pois a ajuda ao próximo é baseada na solidariedade, que é facultativa, enquanto a conquista da Educação Infantil está na legislação, como dever do Estado e direito do cidadão. Com tais premissas, Montaño (2005, p. 168) afirma que se desenvolve "um verdadeiro processo de esvaziamento da dimensão de 'conquista' e de 'direito' das políticas sociais."

No que se refere às justificativas "Atendimento fácil" e "Autorização legal", Arelaro $(2008$, p. 61) observa que:

É difícil imaginar que, com todas as facilidades que a regulamentação do Fundeb concedeu às relações público-privadas na educação, as esferas públicas empenhem-se para construir alternativas de atendimento diferentes das que se vêm consagrando como as mais ágeis e viáveis para o atendimento, em especial o emergencial, das crianças pequenas, com a significativa (des)responsabilização do Estado pelo atendimento educacinal direto. 
A autora nos leva a refletir sobre o fato de que, com os convênios, o município não precisa contratar professores, fugindo assim da Lei de Responsabilidade Fiscal. A prefeitura também fica dispensada da instalação da infraestrutura adequada, uma justificativa usada em $16 \%$ dos casos (como podemos observar no gráfico acima), o que revela outro ponto frágil na oferta de Educação Infantil.

Como dissemos na introdução deste trabalho, o direito à Educação Infantil foi adquirido, mas sua concretização nem sempre tem sido fácil, principalmente para os municípios que são os responsáveis por essa etapa da educação básica, com o auxílio do estado e da União (BRASIL, 1996, art. 11). Como o município tem a menor parcela dos recursos entre as outras instâncias do poder, a Educação Infantil pode ficar prejudicada.

Arelaro (2008), também nos alerta para o fato de que os gastos com as creches públicas são mais altos que os gastos com as creches privadas conveniadas, e o índice do coeficiente do Fundeb para a Educação Infantil é menor que os destinados ao Ensino Fundamental. Assim, o município com poucos recursos para prover a Educação Infantil tende a realizar o convênio como uma opção mais barata, o que pode estar nas entrelinhas da justificativa "Atendimento fácil".

Em relação à justificativa "Autorização legal”, ao facilitar a implementação de parcerias, conforme ressaltado por Arelaro (2008), o Fundeb permite a transferência de recursos às instituições privadas, o que "representa um duro golpe no princípio de que recursos públicos devem se destinar às instituições públicas" (PINTO, 2007, p. 888).

Consideramos também, assim como Arelaro (1999) e Borghi (2005), que a municipalização do Ensino Fundamental, decorrente principalmente da criação do Fundef, fez com que os municípios priorizassem esse nível escolar e deixassem em segundo plano a Educação Infantil, reforçando as tradicionais parcerias com instituições privadas para o atendimento à primeira infância.

De acordo com Borghi, Adrião e Arelaro (2009), a legislação atualmente reconhece e afirma o estabelecimento de convênios quando se trata de educação para a faixa etária de 0 a 3 anos. Essa política serve como incentivo para a continuidade das parcerias, que são menos onerosas e demandam menos esforços da administração pública municipal, fato que podemos constatar por meio das 
justificativas registradas neste trabalho, principalmente a da "Autorização legal" e a do "Atendimento fácil".

Quanto à preocupação com a qualidade dos serviços prestados pelas instituições conveniadas, podemos observar que apenas um município declarou ter firmado convênio porque a instituição oferece um "bom atendimento" às crianças.

Nos contatos telefônicos para a obtenção de informações, raramente ouvimos dos municípios alguma colocação que demonstrasse preocupação com a qualidade do atendimento nas creches conveniadas. Um município afirmou que a instituição conveniada é responsável pelas "necessidades, características de desenvolvimento e aprendizagem das crianças"; outro explicou que a "Secretaria Municipal de Educação exige que a creche conveniada siga as mesmas normas das creches municipais, como, por exemplo, professores com formação mínima na creche, número de alunos por sala, entre outras normas". No restante dos municípios, não se verificou nenhuma menção à preocupação com a qualidade do serviço prestado pelas entidades conveniadas.

Como relata Gouveia (2009, p. 46),

$\mathrm{Na}$ literatura recente ou nas experiências divulgadas, não foram encontrados argumentos quanto à pertinência da realização de convênios por razões pedagógicas ou de estratégia de autogestão comunitária, argumentos esses que poderiam aproximar-se de teses desestatizantes à esquerda.

Em contraposição à justificativa neoliberal para a opção pelo convênio, vemos que os municípios não utilizam as creches conveniadas por estas serem uma forma de atendimento melhor e mais eficiente que $o$ atendimento público. Tampouco observamos, atualmente, a motivação apontada por Costa $(2005$, p.17) para o surgimento, nas décadas de 1970 e 1980, de instituições do terceiro setor no ramo da educação. Esta motivação, como já indicado anteriormente, teria como fatores principais a preocupação com a "dominação social e reprodução do status quo", com a qual a sociedade civil buscava romper a partir do discurso antiescolar. Assim, com base nas justificativas apontadas nesta pesquisa, o que vemos atualmente, nos municípios pesquisados, é um descaso com estas preocupações acima citadas como motivação para a entrada do terceiro setor no ramo da educação nas décadas de 70 e 80; pois as justificativas levantadas por esta pesquisa não fazem referência 
à qualidade da educação e muito menos ao rompimento da reprodução do status quo.

Dessa forma, as justificativas para a opção pelo convênio levantadas nesta pesquisa mostram que os municípios não tratam a qualidade como fator principal, ou mesmo secundário, quando firmam convênio com instituições privadas sem fins lucrativos, um fato também constatado em pesquisas anteriores realizadas em vários estados brasileiros (DOMICIANO, 2009; OLIVEIRA, 2010; COSTA, 2005).

Um exemplo dessas pesquisas é a de Costa (2005, p. 23-24), feita na cidade do Rio de Janeiro, onde se encontra a mesma displicência na preocupação com a qualidade do atendimento às crianças, seja em relação à infraestrutura, seja no que diz respeito à parte pedagógica. $\mathrm{O}$ autor ressalta que:

Pode-se dizer que a extensão do programa atendia muito mais à agenda política dos secretários de chefes intermediários do que a uma perspectiva de atendimento de um direito básico da população. As crianças e as condições em que seriam atendidas também não eram elementos centrais nas decisões tomadas. [...] Não havia qualquer ênfase na necessidade de desenvolver um trabalho pedagógico com padrões razoáveis de qualidade, mesmo que em condições materiais diversas.

Arelaro (2008, p. 62) se refere à preocupação com a qualidade do atendimento à demanda por Educação Infantil da seguinte forma:

\footnotetext{
É verdade que a lei estabelece que tais instituições deverão "atender a padrões mínimos de qualidade definidos pelo órgão normativo do sistema de ensino, e obrigatoriamente ter aprovado seus projetos pedagógicos" (BRASIL, 2007a, art. 15, $\S 2^{\circ}$ inciso IV); porém, os próprios dirigentes municipais de educação admitem que esta exigência, ainda que meritória, é inócua, pois os municípios só estabelecem essa parceria por não disporem de vagas em seus estabelecimentos.
}

Em consonância ao que é relatado por Arelaro, podemos observar, pelo gráfico desta pesquisa, que o primeiro lugar entre as justificativas dos dirigentes das Secretarias Municipais de Educação é ocupado pela "Demanda", ou seja, uma necessidade de vagas que a rede municipal não consegue suprir. Entre os 15 municípios que declararam optar pelo atendimento conveniado para atender à demanda por creche, três não tinham instituições municipais para a faixa etária, de modo que o atendimento educacional de crianças de 0 a 3 anos era realizado exclusivamente pelas instituições parceiras. 
Como mencionamos na introdução deste trabalho, tal justificativa demonstra que os municípios realizam o convênio por não serem capazes de absorver a demanda por Educação Infantil. Os exemplos de Domiciano (2009) e Oliveira (2010) evidenciam a predominância da mesma justificativa para a opção pelo convênio nos municípios que pesquisaram.

\section{CONSIDERAÇÕES FINAIS}

Com os dados e premissas aqui abordados, consideramos ser possível responder à pergunta inicial que suscitou este artigo: a supremacia da gestão local e da participação comunitária, proposta nas décadas de 1970 e 1980, ou o diagnóstico neoliberal de maior eficiência, maior competitividade e menor custo do setor privado atual aparecem nas justificativas para as parcerias entre o setor público e o privado no conjunto de municípios pesquisados?

Da mesma forma que Borghi (2012) e Costa (2005), consideramos que a ausência histórica do Estado, que deu espaço à proliferação dos convênios com base no discurso de maior participação local e comunitária, se distingue do que ocorre no momento atual, em que há uma efetiva política de responsabilização da esfera privada pela oferta de Educação Infantil por meio da subvenção pública não só às instituições sem fins lucrativos como também às instituições privadas com finalidade lucrativa (DOMICIANO, 2009; OLIVEIRA, 2010). Como pudemos ver, em favor do atendimento rápido à demanda, essa subvenção não só desobriga o Estado com relação à Educação Infantil como desvaloriza esse nível educacional e desconsidera a essencial qualidade de ensino determinada pela legislação.

Finalizamos este artigo salientando a forte presença do ideário neoliberal que exalta o setor privado em detrimento do setor público. Essa desqualificação do setor público, embasada na lógica neoliberal, atualmente tem levado à descentralização das "operações do Estado" e, em consequência, à "distribuição de grandes fundos públicos para o setor privado" (MORAES, 2002, p. 18).

Moraes (2002, p. 20) considera a supremacia do privado da seguinte forma: "A proposta neoliberal de 'reforma' dos serviços públicos, como se sabe, é orientada por uma ideia regulatória: a ideia de privatizar, isto é, de acentuar o primado e a superioridade da ratio privada sobre as deliberações coletivas." 
Exemplo disso é o próprio repasse de recursos públicos para instituições privadas sem fins lucrativos de Educação Infantil nos municípios paulistas onde o setor público não é "eficiente" (do ponto de vista neoliberal). Consideramos que iniciativas como a transferência do atendimento educacional para o setor privado, por meio da descentralização da oferta de vagas e da distribuição de recursos para as creches conveniadas, são "formas de induzir o ethos privado do mercado no reino das funções públicas" (MORAES, 2002, p. 20).

\section{BEATRIZ APARECIDA DA COSTA}

Graduada em Pedagogia pela Universidade Estadual Paulista Júlio de Mesquita Filho - Rio Claro. Mestranda em Educação nesta mesma instituição. Membro do Grupo de Estudos e Pesquisa em Política Educacional (GREPPE).

\section{RAQUEL FONTES BORGHI}

Graduada em Pedagogia pela Universidade Estadual Paulista - Araraquara, Mestre em Educação Escolar pela Universidade Estadual Paulista Júlio de Mesquita Filho e Doutora pela mesma universidade. Professora assistente da Universidade Estadual Paulista - Rio Claro. Coordenadora do GREPPE em Rio Claro.

\section{REFERÊNCIAS}

ADRIÃO, T. (coord.) Estratégias municipais para a oferta da educação básica: as parcerias público-privadas. Relatório de pesquisa: Fapesp. 2009.

ADRIAO, T.; ARELARO, L. R. G. ; BORGHI, R. ; GARCIA, T. O. A simbiose entre as prefeituras paulistas e o setor privado: tendências e implicações para a política educacional local. In: Anais da 33a. Reunião Nacional de Pós-Graduação e pesquisa em educação "Educação no Brasil: balanço de uma década, 2010. v. 1. p. $1-14$.

ADRIÃO, T; GARCIA, T.; BORGHI, R.; ARELARO, L. Estratégias municipais para a oferta da Educação Básica: Análise das parcerias público-privado no estado de São Paulo. Relatório de pesquisa. Fapesp, 2009.

ARELARO, L. A não-transparência nas relações público-privadas: o caso das creches conveniadas. In: ADRIÃO, T.; PERONI, V (Org.). Público e Privado na Educação: novos elementos para o debate. 1 ed. São Paulo: Xamã, 2008, v. 1, p. 51-66.

BORGHI, R. F. Oferta Educacional nas creches: Arranjos Institucionais entre o Público e o Privado. Relatório de Pesquisa. 2012. 
BORGHI, R. F. Municipalização do ensino e valorização do magistério no interior paulista - um estudo em dez municípios. 2005. 206 f. Tese de doutorado Universidade Estadual Paulista - Faculdade de Ciências e Letras de Araraquara. Araraquara, 2005.

BORGHI, R.; ADRIÃO, T.; ARELARO, L. A relação público-privada na oferta da Educação infantil: continuidades e rupturas. In: XXIV Simpósio Brasileiro e III Congresso Interamericano de Política e Administração da Educação, 2009, Vitória. Direitos Humanos e Cidadania: desafios para as políticas públicas e a gestão democrática da educação. Vitoria. Porto Alegre: Anpae, 2009. v. 08. p. 1-19.

BRASIL. Congresso Nacional. Constituição da República Federativa do Brasil. Brasília: Senado Federal/Centro Gráfico, 1988.

BRASIL. Lei Complementar $n^{\circ} 101$, de 04 de maio de 2000 . Lei de Responsabilidade Fiscal de 04/05/2000. Estabelece normas de finanças públicas voltadas para a responsabilidade na gestão fiscal e dá outras providências. Disponível em: <http://www.planalto.gov.br/ccivil_03/Leis/LCP/Lcp101.htm> Acesso em: 20 de agosto de 2011.

BRASIL. Lei no. 8.069, de 13/07/1990. Dispõe sobre o Estatuto da Criança e do Adolescente e dá outras providências. Brasília, 1990.

BRASIL, Lei $\mathbf{n}^{\circ}$ 4.024, de 20 de dezembro de 1961. Fixa as Diretrizes e Bases da Educação Nacional. Disponível em: <http://www.histedbr.fae.unicamp.br/navegando/fontes_escritas/6_Nacional_Desenv olvimento/ldb\%20lei\%20no\%204.024,\%20de\%2020\%20de\%20dezembro\%20de\%20 1961.htm> Acesso em: 08 de setembro de 2010.

BRASIL. Lei $\mathbf{n}^{\circ}$. 9.424, de 24 de dezembro de 1996. Institui o Fundo de Manutenção e Desenvolvimento do Ensino Fundamental e Valorização do Magistério. Brasília, 1996. Diário Oficial da União. Brasília, 25 de dezembro de 1996.

BRASIL. Lei $\mathbf{n}^{\circ}$ 11.494, de 20 de junho de 2007. Regulamenta o Fundo de Manutenção e Desenvolvimento da Educação Básica e de Valorização dos Profissionais da Educação - FUNDEB. Disponível em: <http://abrelivros.publier.com.br/abrelivros/dados/anexos/4235.pdf> Acesso em: 19 de outubro de 2010.

COSTA, B. A. Oferta Educacional nas creches e Parcerias Público-Privado nos municípios paulistas de $\mathbf{1 0 . 0 0 1}$ a $\mathbf{5 0 . 0 0 0}$ habitantes. 2011, $147 \mathrm{f}$.. Monografia de conclusão de curso - Universidade Estadual Paulista - Instituto de Biociências de Rio Claro. Rio Claro, 2011.

COSTA, M. Criar o público não-estatal ou tornar público o estatal?. In: Theresa Adrião; Vera Peroni, (org). O público e o privado na educação. Interfaces entre Estado e Sociedade. São Paulo: Xamã, 2005, p.13 - 30 
DOMICIANO, C. A. O Programa Bolsa Creche nos municípios paulistas de Piracicaba e Hortolândia: uma proposta para alocação de recursos estatais à educação privada?. 2009. 228 f.. Dissertação de Mestrado - Universidade Estadual Paulista - Instituto de Biociências de Rio Claro. Rio Claro, 2009.

FULLGRAF, J. B. G. O lugar da Educação infantil na sociedade contemporânea. Ciências e letras, Porto Alegre, n. 43, p. 25-40, jan./jun. 2008.

GOUVEIA, A. B. Direita e esquerda na política educacional: democracia, partidos e disputas entre projetos de administração pública municipal no Brasil. Revista Brasileira de Estudos Pedagógicos, Brasília, v. 90, n. 224, p. 32-58, jan./abr. 2009.

GREPPE. Banco de Dados do Greppe. Disponível em: <http://www.rc.unesp.br/ib/educacao/greppe/> Acesso em: 22 de junho de 2011.

MORAES, R. C. Reformas neoliberais e políticas públicas: hegemonia ideológica e redefinição das relações Estado-sociedade. Educação e Sociedade, Campinas, vol. 23, n. 80, setembro/2002, p. 13-24. Disponível em http://www.scielo.br/pdf/es/v23n80/12921.pdf. Acesso em: 26 de agosto de 2012.

MONTAÑO, C. Terceiro setor e a questão social: crítica ao padrão emergencial de intervenção social. $3^{a}$ ed. São Paulo: Cortez Editora, 2005, 288 p.

OLIVEIRA, J. S. Oferta Educacional nas creches e Parcerias Público-Privado nos municípios paulistas de $\mathbf{1 0 0 . 0 0 0}$ a $\mathbf{5 0 0 . 0 0 0}$ habitantes. 2010, $158 \mathrm{f}$. Monografia de conclusão de cursos - Universidade Estadual Paulista - Instituto de Biociências de Rio Claro. Rio Claro, 2010.

PINTO, J. M. A política recente de fundos para o financiamento da educação e seus efeitos no pacto federativo. Educação \& Sociedade, 28 n.100 Campinas out. 2007 p. $877-897$

SUSIN, M. O. O estatal e o público não estatal: onde esta a Educação infantil comunitária em Porto Alegre? In: PERONI, V. M. V.; ADRIÂO, T.; (org). Público e Privado na educação: novos elementos para o debate. 1 ed. São Paulo: Xamã, 2008. p. 67-78. 